\title{
A drug utilization study of analgesics for management of postoperative pain in patients admitted at a tertiary care teaching hospital
}

\author{
Jignesh S. Chaudhari*, Amita R. Kubavat, Vimesh R. Mistry, Ashna S. Pandya, \\ S. C. Hotchandani, Brijal S. Patel
}

\author{
Department of Pharmacology, \\ P.D.U. Government Medical \\ College, Rajkot, Gujarat, India \\ Received: 10 September 2013 \\ Accepted: 21 September 2013 \\ *Correspondence to: \\ Dr. Jignesh S. Chaudhari, \\ Email: \\ jigneshchaudhari314@yahoo.com \\ (C) 2013 Chaudhari JS et al. This \\ is an open-access article \\ distributed under the terms of \\ the Creative Commons \\ Attribution Non-Commercial \\ License, which permits \\ unrestricted non-commercial \\ use, distribution, and \\ reproduction in any medium, \\ provided the original work is \\ properly cited.
}

\begin{abstract}
Background: Postoperative pain is very common and develops naturally as a warning. After surgery, its development can be predicted and should be prevented and treated. Besides the disagreeable aspects and physiological repercussions of postoperative pain, it delays ambulation and hospital discharge. Despite the drugs and anesthetic techniques available, the prevalence of postoperative pain is still high.

Methods: Pain assessment was done by BP cuff inflation method and Numerical rating scales both pre and postoperatively.

Results: Complain of postoperative pain is more in female patient. Over all complain of postoperative pain was observed more in 31-45 year age group. Complain of postoperative pain was more at 18 hour time interval. Postoperative pain complains was more in patients undergoing general surgery. Postoperatively out of 310 patients 298 patients were received diclofenac only and 18 patients were received diclofenac + tramadol combination of these 112 and 13 patients complained of post-operative pain respectively.

Conclusions: 112 patients from diclofenac only received group and 13 patients from diclofenac + tramadol received group complain of post operative pain. Postoperative pain control at 12 hours is sufficient but high post-operative pain scores at 18 hour of post-operative time interval suggesting needs of additional pain control. Majority of study patients received single analgesic (Diclofenac sodium).
\end{abstract}

Keywords: Postoperative pain, Numerical rating scale, BP cuffs inflation method

\section{INTRODUCTION}

The international Association for the study of pain defines pain as "An unpleasant sensory and emotional experience associated with actual or potential tissue damage, or described in term of damage". ${ }^{1}$

The response to pain can be highly variable between persons as well as in the same person at different times. ${ }^{1}$

Pain can be classified according to duration (acute or chronic) pathophysiology (e.g., nociceptive or neuropathic pain), etiology (e.g., postoperative or cancer pain), or affected area (e.g., headache or low back pain). Such classification are useful in the selection of treatment modalities a drug therapy. 1,2

Postoperative pain is considered a form of acute pain due to the surgical trauma with inflammatory reaction. ${ }^{3}$
Postoperative pain involves multiple physiological mechanisms and is a combined constellation of severe unpleasant sensory, emotional and mental experiences precipitated by the surgical trauma and associated with autonomic, endocrine-metabolic, physiological and behavioral responses. $^{3}$

Considering the lack of knowledge about the magnitude of postoperative pain in our hospitals, a study to evaluate the postoperative pain in the patients undergone various surgery in different departments of P.D.U. Government Hospital Rajkot was selected.

\section{METHODS}

This is an observational, longitudinal study conducted at P.D.U. Govt. Hospital, Rajkot from March 2011 to May 2012 duration. The approval of institutional ethics committee was taken before start of study. 
Patients were enrolled as per below mentioned criteria.

\section{Inclusion criteria}

1. Patients undergoing various operative procedures (General surgery, obstetrics \& gynecology surgery and orthopedic surgery) in P.D.U. Government Hospital, Rajkot.

2. Patients with hospital stay of minimum 24 hours.

3. Patients willing to give consent.

\section{Exclusion criteria}

1. History of allergy to analgesic.

2. Patient receives analgesic within 7 days to operation.

3. Patient on glucocorticoids.

4. Peptic ulcer patient.

5. Alcoholic patient.

6. Chronic inflammatory condition like rheumatoid arthritis, psoriasis, Systemic lupus erythematous, atherosclerosis, chronic obstructive pulmonary disease, irritable bowel disease, celiac disease.

Pain assessment was done by

\section{BP cuff inflation method ${ }^{4}$}

In this method, the BP cuff is tied to the forearm with the cap of a cold drink bottle under the cuff with its edges directly applied to the skin. The cuff is inflated and the time at which the pain feels on skin with the cold drink cap edge on skin is noted as pain threshold.

\section{Numerical rating scales $(N R S)^{5}$}

An NRS typically consists of a series of numbers with verbal anchors representing the entire possible range of pain intensity.

Generally, patients rate their pain from 0 (no pain) to 10 (maximum pain).
All the patients were made familiar with a Numerical Rating scale and BP cuff inflation method on preoperative assessment to assess their pre-operative pain severity score.

Preoperative assessment - Preoperatively in all patients pain is artificially produced by BP cuff inflation method and at which point patient start feeling pain is noted as pain score.

Postoperative assessment - Postoperatively pain score is noted by BP cuff inflation method after patient undergoing operative procedure at $0-1$ hours, 6 hours, 18 hours and 24 hours. Post-operatively Numerical Rating scale were used to note pain score at $0-1$ hours, 6 hours, 18 hours and 24 hours along with BF cuff inflation method.

We used one way ANOVA test for the comparison of the pre and postoperative pains core.

\section{RESULTS}

Total enrolled patients are $310(\mathrm{M}=176, \mathrm{~F}=134)$. Out of these $125(40.32 \%)$ patients complain of postoperative pain $\{(M=62(35.22 \%), F=63(41.01 \%)\}$. Female patients complain of more postoperative pain compared to male [Female (47.01\%)>Male (35.22\%)]. Among male patients $42(67.74 \%)$ complained postoperative pain at 18 hours time interval, same result $49(77.77 \%)$ also observed in female patients at same time interval. Over all complain of postoperative pain was observed more at 18 hour time interval $91(72.8 \%)$. Over all complain of postoperative pain was observed more in $31-45$ year age group 67(53.6\%).

Among various surgeries postoperative pain complain was more in patients undergoing general surgery $86(68.8 \%)$.

Sensitivity of pain is more in female patients than male patients in both pre and post-operative period and is statistically significant (One way ANOVA, p- value, Male $=0.0139$, Female $=0.0134)$.

Table 1: Pain score pre and postoperatively in different gender at different time interval by BP cuff inflation method.

\begin{tabular}{|llllll|}
\hline \multirow{7}{*}{ Sex } & \multirow{2}{*}{ Pain score $(\mathrm{mmHg})$, Mean \pm SD } & & \\
& Preoperative & Postoperative & & \\
\cline { 3 - 6 } & & $0-1$ hour & 6 hours & 18 hours & 24 hours \\
\hline Male & $57.18 \pm 8.49$ & $57.35 \pm 8.43$ & $57.58 \pm 8.33$ & $56.87 \pm 10.4$ & $59.94 \pm 9.97$ \\
\hline Female & $55.18 \pm 7.93$ & $54.92 \pm 7.92$ & $54.77 \pm 8.20$ & $53.02 \pm 9.63$ & $56.71 \pm 8.96$ \\
\hline
\end{tabular}

$($ One way ANOVA, p- value, Male $=0.0139$, Female $=0.0134)$ 
Table 2: Pain score pre and postoperatively in various age groups at different time interval by BP cuff inflation method.

\begin{tabular}{|llllll|}
\hline \multicolumn{7}{|c|}{ Pain score $(\mathrm{mmHg})$, Mean \pm SD } \\
Age (years) & \multirow{2}{*}{ Preoperative } & Postoperative & & \\
\cline { 3 - 6 } & & $0-1$ hour & 6 hours & 18 hours & 24 hours \\
\hline $16-30$ & $52.66 \pm 8.62$ & $48.70 \pm 4.2$ & $48.62 \pm 4.35$ & $45.80 \pm 5.88$ & $49.43 \pm 5.51$ \\
\hline $31-45$ & $52.42 \pm 5.51$ & $52.00 \pm 4.33$ & $52.00 \pm 4.8$ & $49.76 \pm 5.76$ & $53.73 \pm 5.66$ \\
\hline $46-60$ & $59.11 \pm 6.81$ & $60.33 \pm 5.89$ & $60.44 \pm 5.93$ & $60.88 \pm 7.21$ & $63.72 \pm 6.68$ \\
\hline$>60$ & $64.01 \pm 8.06$ & $67.40 \pm 5.86$ & $67.74 \pm 5.85$ & $68.03 \pm 6.71$ & $70.58 \pm 6.37$ \\
\hline
\end{tabular}

(One way ANOVA, p- value, $16-30$ years $=0.0001,31-45$ years $=0.0001,45-60$ years $=0.0001,>60$ years $=0.0001)$.

Table 3: Pain score in different gender and in different age group at different time interval by Numerical rating scale.

\begin{tabular}{|c|c|c|c|c|c|c|}
\hline \multirow{3}{*}{$\begin{array}{l}\text { Time } \\
\text { interval } \\
\text { in hours }\end{array}$} & \multicolumn{6}{|c|}{ Postoperative pain score, Mean \pm SD } \\
\hline & \multicolumn{2}{|c|}{ Different gender } & \multicolumn{4}{|c|}{ Different age group } \\
\hline & Male patient & Female patient & 16-30 years & $31-45$ years & $46-60$ years & $>60$ years \\
\hline $0-1$ & $4.64 \pm 0.49$ & $4.66 \pm 0.48$ & $4.93 \pm 0.24$ & $4.82 \pm 0.40$ & $4.57 \pm 0.49$ & $4.06 \pm 0.31$ \\
\hline 6 & $4.61 \pm 0.51$ & $4.69 \pm 0.53$ & $4.96 \pm 0.31$ & $4.85 \pm 0.45$ & $4.52 \pm 0.50$ & $4.04 \pm 0.28$ \\
\hline 18 & $4.70 \pm 1.03$ & $5.10 \pm 0.53$ & $5.66 \pm 0.65$ & $5.26 \pm 0.83$ & $4.36 \pm 0.85$ & $3.78 \pm 0.76$ \\
\hline 24 & $4.09 \pm 0.82$ & $4.25 \pm 0.82$ & $4.27 \pm 0.58$ & $4.25 \pm 0.63$ & $4.78 \pm 0.67$ & $3.31 \pm 0.61$ \\
\hline
\end{tabular}

Table 4: Analgesic prescribing pattern and postoperative pain complain among them.

\begin{tabular}{|lll|}
\hline $\begin{array}{l}\text { Analgesic prescribing } \\
\text { pattern to treat } \\
\text { postoperative pain }\end{array}$ & $\begin{array}{l}\text { No. of } \\
\text { patient }\end{array}$ & $\begin{array}{l}\text { No. of patients } \\
\text { complain of } \\
\text { Postoperative } \\
\text { pain complain }\end{array}$ \\
\hline $\begin{array}{l}\text { Diclofenac } 50 \mathrm{mg} \\
\text { oral } 12 \text { hourly }\end{array}$ & 180 & 98 \\
\hline $\begin{array}{l}\text { Diclofenac } 50 \mathrm{mg} \\
\text { oral } 8 \text { hourly }\end{array}$ & 30 & 3 \\
\hline $\begin{array}{l}\text { Diclofenac } 75 \mathrm{mg} \\
\text { IM12 hourly }\end{array}$ & 14 & 10 \\
\hline $\begin{array}{l}\text { Diclofenac 75 mg } \\
\text { IM } 8 \text { hourly }\end{array}$ & 68 & 1 \\
\hline $\begin{array}{l}\text { Diclofenac } 50 \mathrm{mg} \text { oral } \\
12 \text { hourly + Tramadol } 1 \\
\text { amp in NS iv infusion }\end{array}$ & 7 & 7 \\
\hline $\begin{array}{l}\text { Diclofenac 75 mg } \\
\text { IM } 8 \text { hourly + Tramadol } \\
\text { 1amp in NS iv infusion }\end{array}$ & 11 & 6 \\
\hline
\end{tabular}

In age group of 16-45 years postoperative pain threshold were low (pain fell at low $\mathrm{mmHg}$ ) as compared to preoperative pain threshold feel and is statistically extremely significant. In 45-60 years age group and >60 years age group postoperative pain threshold were high (pain feel at high $\mathrm{mmHg}$ ) compared to preoperative pain feel and is statistically extremely significant. (One way ANOVA, p- value, 16-30 years $=0.0001,31-45$ years $=$ $0.0001,45-60$ years $=0.0001,>60$ years $=0.0001$ ).

In patients undergo obstetrics \& gynecology and patients undergo orthopedic surgery preoperative and postoperative pain feel at low pain threshold compared to patients undergo general surgery.

Postoperative pain score measured by numerical rating scale showed more pain score in female patients at 18 hours interval only while no differences in rest results.

In our study, out of 310 patients enrolled majority patients (292) received the single non opioid analgesic drug (diclofenac sodium) while only few number of patients (18) received combination of drugs (opioid and nonopioid drug). 112 patients complained of postoperative pain in single drug received group while 13 patients from combination drug received group. 
Table 5: Pain score preoperatively and postoperatively in drug prescribing group at different time interval by BP cuff inflation method.

\begin{tabular}{|c|c|c|c|c|c|}
\hline \multirow{3}{*}{$\begin{array}{l}\text { Drug } \\
\text { prescribed } \\
\text { to treat } \\
\text { postoperative } \\
\text { pain }\end{array}$} & \multicolumn{5}{|c|}{ Pain score $(\mathrm{mmHg})$, Mean \pm SD } \\
\hline & \multirow{2}{*}{ Preoperative } & \multicolumn{4}{|l|}{ Postoperative } \\
\hline & & 0-1 hour & 6 hours & 18 hours & 24 hours \\
\hline Group A & $57.19 \pm 8.45$ & $57.24 \pm 8.55$ & $57.33 \pm 8.62$ & $54.85 \pm 10.95$ & $\begin{array}{l}58.76 \pm \\
10.16\end{array}$ \\
\hline Group B & $57.15 \pm 8.44$ & $57.20 \pm 8.54$ & $57.25 \pm 8.62$ & $54.80 \pm 10.94$ & $58.71 \pm 10.15$ \\
\hline Group C & $55.36 \pm 7.49$ & $55.86 \pm 7.52$ & $56.08 \pm 7.46$ & $56.81 \pm 8.22$ & $59.56 \pm 7.94$ \\
\hline Group D & $52.5 \pm 7.27$ & $52.5 \pm 7.27$ & $52.5 \pm 7.27$ & $51.40 \pm 7.70$ & $53.2 \pm 8.90$ \\
\hline Group E & $48.63 \pm 4.52$ & $48.63 \pm 4.52$ & $46.56 \pm 5.95$ & $49.54 \pm 7.56$ & $52.72 \pm 6.06$ \\
\hline Group F & $46.42 \pm 2.49$ & $46.42 \pm 2.49$ & $46.42 \pm 2.49$ & $41.42 \pm 2.44$ & $45.71 \pm 3.45$ \\
\hline
\end{tabular}

(One way ANOVA, p- value, $\mathrm{A}=0.0034, \mathrm{~B}=0.0132, \mathrm{C}=0.0136, \mathrm{D}=0.9834, \mathrm{E}=0.2263, \mathrm{~F}=0.0049$ )

Group A - Diclofenac $50 \mathrm{mg}$ oral 8 hourly

Group B - Diclofenac $50 \mathrm{mg}$ oral 12 hourly

Group C - Diclofenac 75 mg IM 8 hourly

Group D - Diclofenac 75 mg IM 12 hourly

Group E - Diclofenac 75 mg IM 8 hourly + Tramadol 100 mg in NS IV infusion

Group F - Diclofenac 50 mg oral 12 hourly + Tramadol $100 \mathrm{mg}$ in NS IV infusion

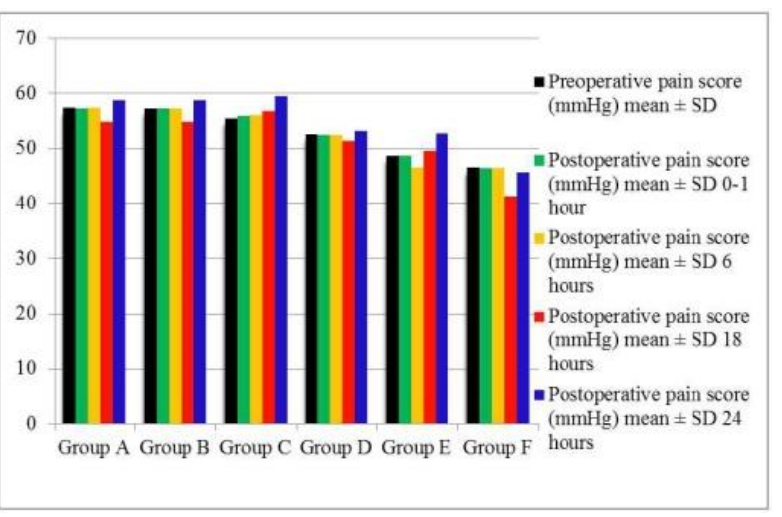

Figure 1: Pain score preoperatively and postoperatively in drug prescribing group at different time interval by BP cuff inflation method.

Group A - Diclofenac 50 mg oral 8 hourly Group B - Diclofenac $50 \mathrm{mg}$ oral 12 hourly Group C - Diclofenac 75 mg IM 8 hourly

Group D - Diclofenac 75 mg IM 12 hourly

Group E - Diclofenac 75 mg IM 8 hourly + Tramadol $100 \mathrm{mg}$ in NS IV infusion

Group F - Diclofenac $50 \mathrm{mg}$ oral 12 hourly + Tramadol $100 \mathrm{mg}$ in NS IV infusion

Majority patients (252) patients received bupivacaine followed by 45 patients sodium thiopentone, 9 patients succinylcholine. 2 patients received propofol while 1 patient lignocaine hydrochloride and 1 patient received ketamine.
Out of 8 drugs used 4 drugs bupivacaine, Lignocaine hydrochloride, propofol, ketamine are present in WHO essential medicine list and all 8 drugs are present in National essential medicine list. All patients were prescribed drug by generic name.

\section{DISCUSSION}

Study results revealed that postoperative pain was more noted in the female than male patients enrolled in the study [Female $(47.01 \%)$, Male $(35.22 \%)$ ]. It was also observed in a study by Taenzer $\mathrm{AH}$ et $\mathrm{al}^{6}$ and Uchiyama $\mathrm{K}$ et al. ${ }^{7}$

Over all complain of postoperative pain was observed more in 31-45 year age group 67(53.6\%). Same observation is seen in study done by Sttots NA et al. ${ }^{8}$ Over all complain of postoperative pain observed $\{91(72.8 \%)\}$ was at 18 hour time post-operatively.

Postoperative pain complain was more in patients undergo general surgery $86(68.8 \%)$ and among them more in male patients $46(54.48 \%)$. It was also observed in study by Menezes Couceiro TC et al. ${ }^{9}$

Patients undergo obstetrics \& gynecology and orthopedic surgery preoperative and postoperative pain threshold were low (pain feel at low mmHg) compared to patients undergo general surgery. It was also observed in study by Menezes Couceiro TC et al. ${ }^{9}$ 
Mean pain score was higher with female then male (Table 1) same observation also supported by another study done by Menezes Couceiro TC et al. ${ }^{9}$

In 16-45 year age group postoperative pain threshold were low (pain fell at low $\mathrm{mmHg}$ ) compare to preoperative pain threshold. In 45-60 year and >60 years age group postoperative pain threshold were high (pain fell at high $\mathrm{mmHg}$ ) compared to preoperative pain threshold (Table 2).

Postoperative pain score measured by numerical rating scale showed more pain score in female patients at 18 hours interval only (Table 3), while no differences in pain score at rest of the time interval. There is evidence in the literature that the pain threshold is lower in women ${ }^{7}$ and their response to painful stimuli differs from males. ${ }^{10}$ As for age, our results differed from those reported by Chung et al. ${ }^{11}$

In the hospital where this study was conducted, analgesics were prescribed according to the preference of the consultants. In study 112 patients complained of post-operative pain in single drug received group while 13 patients from combination drug received group (table 4) same result is seen in study by Ho MK et al. ${ }^{12}$

The medicines in National List of Essential Medicines (NLEM) should be available at affordable costs and with assured quality. ${ }^{14}$ In our study 2 analgesics were used (diclofenac sodium and tramadol) are included in National List of Essential Medicines of India but none included in WHO essential medicine list. ${ }^{13}$

Generic names are international and also used routinely in medical and scientific publications, so prescription by generic name should be encouraged. ${ }^{15}$ In our study drugs prescribed by generic name which is appreciated.

In our study Group A (Diclofenac $50 \mathrm{mg}$ oral 8 hourly) and group F (Diclofenac $50 \mathrm{mg}$ oral 12 hourly + Tramadol 100 $\mathrm{mg}$ in NS IV infusion) showed the statistically very significant difference in the preoperative and postoperative pain score by BP cuff inflation method. Group B (Diclofenac $50 \mathrm{mg}$ oral 12 hourly) and C (Diclofenac 75 mg IM 8 hourly), also showed significant differences in pre and post-operative score same result is seen in study by Barden $\mathrm{J}$ et $\mathrm{al}^{16}$ and Wider smith $\mathrm{CH}$ et al. ${ }^{17}$

\section{CONCLUSION}

In our study out of 310 patients enrolled majority patients (292) received the single non opioid analgesic drug (diclofenac sodium) while only few number of patients (18) received combination of drugs (diclofenac sodium and tramadol). 112 patients complained of post-operative pain in diclofenac sodium received group while 13 patients from diclofenac and tramadol combination drug received group.
Postoperative pain complains are more in female patient than male patient.

Postoperative pain complains is more in age group (1645) years and decrease with increasing age. $40.32 \%$ patients have post-operative pain complain.

Post-operative pain score by BP cuff inflation method were more in patients undergone obstetrics \& gynecology surgeries followed by patients undergo orthopedic surgeries followed by patients undergo general surgeries.

Pain is well controlled in patients receiving Diclofenac 50 mg oral 8 hourly and Diclofenac $50 \mathrm{mg}$ oral 12 hourly + Tramadol $100 \mathrm{mg}$ in NS IV infusion while Diclofenac 75 mg IM 12 hourly and Diclofenac 75 mg IM 8 hourly + Tramadol $100 \mathrm{mg}$ in NS IV infusion did not show any significant difference in pain control.

Post-operative pain control at 12 hours is sufficient but high post-operative pain (in $72.8 \%$ patients) scores at 18 hour of post-operative time interval suggesting needs of additional pain control. All patients are prescribed drug by generic name.

\section{Funding: None \\ Conflict of interest: None declared}

Ethical approval: The study was approved by the Institutional Ethics Committee

\section{REFERENCES}

1. Morgan GE, Mikhail SM, Murray MJ. Clinical anesthesiology. $4^{\text {th }}$ ed.US: McGraw-Hill Companies; 2006. Chapter 18, Pain management; p. 309-18, 338, 341-42, 347.

2. Stoecting RK, Hillier SC. Pharmacology and physiology in anesthetic practice. $4^{\text {th }}$ ed. Philadelphia: Lippincott William and Wilkins; 2006. Chapter 44, Pain; P.714

3. Dahl JB, Kehlet H. Postoperative pain and its management. In, McMahon SB, Koltzenbung M, editors. Wall and Melzack's Textbook of pain. $5^{\text {th }}$ ed. China: Churchill Livingstone; 2006. 635,637.

4. Medhi B, Prakash A. Practical manual of experimental and clinical pharmacology. New Delhi: Jaypee Brothers Medical Publishers (P) Ltd; 2010. Chapter 32, miscellaneous practical's; p.324.

5. Edwards RR, Pain assessment. In, Benzon HT, Raja SN, Molloy RE, Liu SS, Fishman FM. Editors. Essentials of pain medicine and regional anesthesia. 2nd ed. US: Churchill Livingstone Elsevier; 2005. P.29-33.

6. Taenzer AH, Cantwell C, Curry CS. Gender Affects Report of Pain and Function after Arthroscopic Anterior Cruciate Ligament Reconstruction. Anesthesiology 2000;93(3):670-675.

7. Uchiyama K, Kawai M, Tani M, Ueno M, Hama T, Yamaue H. Gender differences in postoperative pain 
after laparoscopic cholecystectomy. Surg Endosc. 2006;20:448-51.

8. Stotts NA, Puntillo K, Hutt JS, Thompson CL, White C. Does age make a difference in procedural pain perceptions and responses in hospitalized adults? Acute Pain September 2007;9(3):125-34.

9. Coucerio TC, Valencs MM, Lima LC, De menezes TC, Roposo MC. Prevalence and influence of gender, age, and type of surgery on postoperative pain. Rev Bras Anestesiol. May/June 2009;59(3):314-20.

10. Ochroch EA, Gottschalk A, Troxel AB, et al. Women suffer more short and long-term pain than men after major thoracotomy. Clin J Pain 2006; 22:491-498.

11. Chung F, Ritchie E, Su J. Postoperative pain in ambulatory surgery. Anesth Analg 1997;85:808816.

12. Ho MK, Chung CH. A prospective, randomised clinical trial comparing oral diclofenac potassium and intramuscular diclofenac sodium in acute pain relief. Hong Kong J Emerg Med. 2004;11:69-77.

13. WHO Model List of Essential Medicines, 17th ed. 2011 March.

14. National List of Essential Medicines, March 2011.

15. Collier J. The cases for and against prescribing generic drugs: generic prescribing benefits patients. BMJ 1988 Dec; 297; 1596-8.

16. Barden J, Edwards J, Moore RA, McQuay HJ. Single dose oral diclofenac for postoperative pain. Cochrane Database of Systematic Reviews [Internet] $2009 \mathrm{rev}$ [cited 2012 nov 05]. Available at http://www. ncbi.nlm.nih.gov/pubmed/15106260.

17. Wilder-Smith CH, Hill L, Dyer RA, Torr G, Coetzee E. Postoperative sensitization and pain after cesarean delivery and the effects of single im doses of tramadol and diclofenac alone and in combination. Anesth Analg. 2003 Aug;97(2):526-33.

doi:10.5455/2319-2003.ijbcp20131216

Cite this article as: Chaudhari JS, Kubavat AR, Mistry VR, Pandya AS, Hotchandani SC, Patel BS. A drug utilization study of analgesics for management of postoperative pain in patients admitted at a tertiary care teaching hospital. Int J Basic Clin Pharmacol 2013;2:757-62. 